DOI 10.31489/2021 No2/90-95

UDC 528.88

\title{
SATELLITE DATA PROCESSING ALGORITHM IN THE PROCESS OF FORMATION OF THE TIME SERIES OF VEGETATION INDEXES
}

\author{
Vitkovskaya I.S., Batyrbayeva M.Zh. \\ Joint-Stock Company "National Center of Space Research and Technology", Almaty, Kazakhstan \\ madina-iki@mail.ru
}

\begin{abstract}
The diverse spectral indexes computed from the satellite images are used extensively in the world practice of remote sensing of the Earth from space. This approach proved its validity for the satellite monitoring of the underlying terrain, detection of ongoing changes and trends of their dynamic patters. Accumulated prodigious amount of satellite data, the state-of-the-art methods of thematic interpretation gave rise to creation of services providing free access to both images and to image processing results. Notwithstanding the foregoing, in the furtherance of the local and regional scale it turns out that usage of the end products of thematic processing of space information supplied by the known available services was not efficient on all occasions. Consequently, we may need to generate our own archives of the long-term series of satellite indexes. The volume of files containing the digital index matrices computed based on the MODIS satellite low resolution data subject to the complete coverage of the territory of Kazakhstan surpasses $4 \mathrm{~Gb}$. This often results in the delayed computations, and on frequent occasions in infeasibility of computation of a full matrix when the medium specs computers are employed. This article is focused on the satellite data processing algorithm in the process of formation of the time series of vegetation indexes. As a consequence, the multi-year archive of vegetation indexes (over a period of 2001-2020), which provided a basis for trend analysis of the underlying terrain, determination of their future trends and forecasting of their changes was created within the territory of the Republic.
\end{abstract}

Keywords: remote sensing, satellite images, processing algorithm, long-term data series, vegetation indexes.

\section{Introduction}

Application of the Earth remote sensing data (ERS) with the aim of location of objects of the underlying terrain of the Earth, subsequent monitoring of these objects, forecasting of changes in their state in the present state of the art of space technologies became a widespread practice already. Study of the multi-year environmental changes with the aid of tools and methods of the remote sensing data represents one of the most promising modern research areas of examination of the processes observed on the Earth's surface. The multizone space images serve as a basis for the interpretation of the spectral characteristic of soil and vegetation covers, water surfaces for the acquisition of reliable data [1].

The current stage of development of space technologies is characterized by the following special patterns of use of satellite data [2]:

- A growing number of the ERS space vehicles, their spectral and spatial resolution made it possible to perform monitoring of the high-rate processes involving detection of such processes at the early stages of development;

- Steep increase in volume and frequency of supply of satellite data [3], which resulted in the necessity for the development of new approaches and methods of the remote sensing data processing practices [4];

- The present-day ERS satellite system ensure acquisition of not only qualitative information but also of accurate quantative information. In view of this, ERS data is used not only for the qualitative assessment of a situation but also for quantitative assessments and the possibility to make predictions of development of the diverse processes and phenomena;

- As a result of the rising level of information accessibility, implementation of the monitoring system has become more profitable than development of the ground-based and aerial surveillance systems;

- There is a trend towards transition from the use of the local systems of data acquisition and creation of own archives of own space images to services of acquisition of information from the large-scale specialized centers.

Specific traits of the present-day development of services offering the remote sensing data are the reason why it is not advantageous to develop and support the entire data processing cycle. Many remote 
sensing systems are targeted at the acquisition of standardized, well-gaged and tailored core products with the previously defined spatial and time formats.

The following differing levels of monitoring - local, regional, national, and global, distinct from each other in their goals - are distinguished. The use of end products of thematic processing of space information in performance of the local and regional tasks does not always prove its efficiency for the spatial and time details of monitoring data. Therefore, a need for the formation of own archives of the long-term series of satellite indexes arises. The volume of files containing the digital index matrices computed based on the MODIS and LANDSAT satellite low resolution data subject to the complete coverage of the territory of Kazakhstan is fairly large. The situation of this sort leads to slowing-down of computations, and in many instances to infeasibility of computation of a full matrix when the low power computers are employed.

This article deals with the technology of generation of the long-term series of vegetation indexes on the basis of satellite data.

\section{Materials and Methods}

\subsection{Satellite Data}

The low-resolution Terra MODIS satellite data, MOD09Q1 [5] product, forming digital matrices of the 8-day aggregates 1 and 2 of spectral channels (wavelength $0.620-0.670 \mu \mathrm{m}$ and $0.841-0.876 \mu \mathrm{m}$, respectively), spatial resolution of $250 \mathrm{~m}$, and sinusoidal projection are applied in this article. The data was processed with the consideration of atmospheric correction, reduced cloud effect and shadows of clouds. The entire territory of Kazakhstan is covered with six granules - 21v03, 21v04, 22v03, 22v04, 23v03, and 23v04 (540 Mb each), Figure 1. Further, a mosaic tile is generated using granules for every channel.

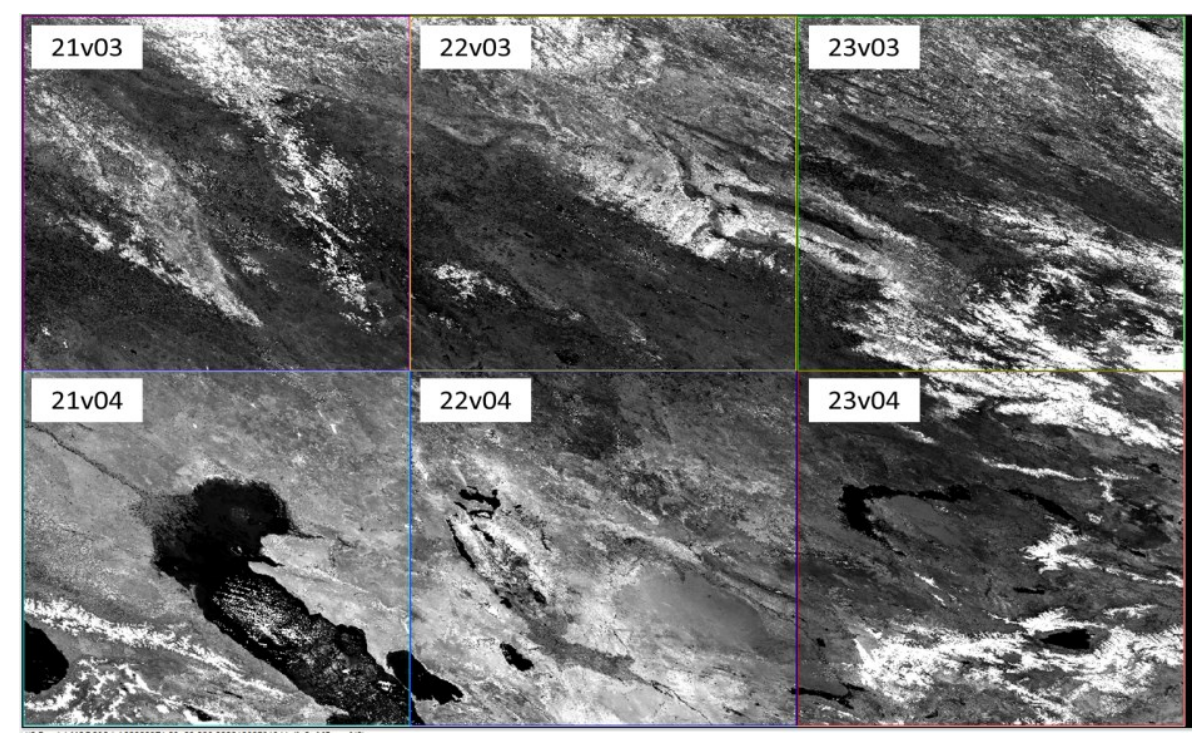

Fig. 1. Layout of granules from the MODIS satellite for the territory of Kazakhstan

\subsection{Research Techniques}

The vegetation index method intended to use satellite data for solution of a wide variety of specific theoretical and applied problems in the course of monitoring of the underlying terrain has been developed in the world practice of remote sensing of the Earth from space. The indexes are selected in an experimental fashion based on the known peculiarities of spectral reflectance curves of soils and vegetation [6-8].

A state of objects of the underlying terrain according to satellite data shall be estimated based on associations of their state with the spectral reflectance characteristics. This becomes most obvious when passing from the visible band $(0.4-0.74 \mu \mathrm{m})$ to the near infrared band $(0.74-1.3 \mu \mathrm{m})$. Application of the method of satellite vegetation indexes for determination of a vegetation response to environment and anthropogenic impact is the common practice of remote sensing of the Earth from space. Existence of the 
long-time series is essential in the area of problems of impact analysis of the state of the underlying terrain. Table 1 lists vegetation indexes applied during satellite monitoring of the vegetation cover of Kazakhstan.

Table 1. Satellite indexes used during satellite monitoring of the vegetative cover of Kazakhstan

\begin{tabular}{|c|c|c|}
\hline Item name & Formula & Intended use \\
\hline $\begin{array}{l}\text { Normalized } \quad \text { Difference } \\
\text { Vegetation Index NDVI [9] }\end{array}$ & $\mathrm{NDVI}=\frac{N I R-R E D}{N I R+R E D}$ & $\begin{array}{l}\text { Assessment of the seasonal dynamics of } \\
\text { state of vegetation cover }\end{array}$ \\
\hline $\begin{array}{l}\text { Vegetation condition index VCI } \\
{[10]}\end{array}$ & $\mathrm{VCI}=\frac{N D V I_{i}-N D V I_{\min }}{N D V I_{\max }-N D V I_{\min }}$ & $\begin{array}{l}\text { Analysis of weather effects on the state of } \\
\text { vegetation cover during the growing season; } \\
\text { weather moisture characteristic }\end{array}$ \\
\hline $\begin{array}{l}\text { Temperature condition index TCI } \\
\text { [11] }\end{array}$ & $\mathrm{TCI}=\frac{B T_{\max }-B T}{B T_{\text {max }}-B T_{\text {min }}}$ & Temperature environment characteristic \\
\hline Vegetation health index VHI [7] & $\mathrm{VHI}=\alpha * \mathrm{VCI}+(1-\alpha)^{*} \mathrm{TCI}$ & $\begin{array}{l}\text { Assessment of the state of vegetation cover } \\
\text { taking into account both temperature } \\
\text { exposure and moisture conditions }\end{array}$ \\
\hline $\begin{array}{l}\text { Integral vegetation index IVI } \\
{[12]}\end{array}$ & $\begin{array}{c}\sum_{t}^{27} N D V I t \\
\text { IVI }={ }_{\substack{\text { number of a ten-day period } \\
\text { during the season }}}\end{array}$ & $\begin{array}{l}\text { Analysis of interseasonal variation of the } \\
\text { state of vegetation }\end{array}$ \\
\hline $\begin{array}{l}\text { Integral vegetation condition } \\
\text { index IVCI [12] }\end{array}$ & $\mathrm{IVCI}=\frac{I V I_{i}-I V I_{\min }}{I V I_{\max }-I V I_{\min }}$ & $\begin{array}{l}\text { Analysis of interseasonal variations of } \\
\text { weather effects on the state of vegetation }\end{array}$ \\
\hline
\end{tabular}

The following values: NIR, RED - reflection factors in the near-infrared region $(0.75-1.0 \mu \mathrm{m})$ and in the read region $(0.55-0.75 \mu \mathrm{m})$ of the spectrum спектра that are corresponding to values 2 and 1 of the channels, respectively, are applied in the formulae. BT means a brightness temperature defined on the basis of thermal channel data in the range of $3.660-14.385 \mu \mathrm{m}$. The $\alpha$ coefficient is either determined empirically or is taken equal to 0.5 . The maximum and minimum values of every index are selected in each pixel throughout the period of monitoring.

\section{Discussion of results}

Usage of ready digital matrices of vegetation indexes provided by the services is not convenient in every instance. For instance, on the U.S. Geological Survey website (USGS) [5] one can find freely available products of the thematic processing of satellite data (NDVI, VCI index matrices) obtained from the MODIS space vehicle (SV) with the spatial resolution of $250 \mathrm{~m}$ (pixel size), 16-daytime period and 20-year archive depth. Meanwhile, Copernicus Land Monitoring Service [13] site intended for registered users of this eservice offers open access to a number of satellite products, inter alia VCI index matrices. The spatial- time resolution of the product is $1-4 \mathrm{~km} / \mathrm{pixel}, 10$-day period. Such spatial-time scale is too small for the tasks of monitoring of the vegetation cover dynamics of local areas.

Generation of own archive of indexes using periodical satellite data at a processing level not below $3 \mathrm{~A}$ [14] is an alternative solution of this problem. This solution provides an opportunity to obtain satellite products required for achievement of the stated goals and objectives. Authors of this article offer their own ERS data processing algorithm to be used in the process of formation of the time series of vegetation indexes with a computation scheme shown in Figure 2.

In the computation of VCI, IVCI indexes of the digital matrices, a preliminary calculation must be performed in every pixel of the long-term maximum and minimum values of NDVI, IVI, respectively, throughout the period of monitoring. $\mathrm{NDVI}_{\min }$ and $\mathrm{IVI}_{\min }$ values are most variable within the territory of Kazakhstan occupying mainly semiarid and arid areas. This fact is attributable to frequently observed dry weather conditions of varying intensity basically in any part of the Republic, which account for such 
suppressed state of vegetation. We should consider updating of time series of the used vegetation indexes from two points of view:

- Computation of values of indexes for every new growing season;

- Re-computation of the entire multi-year archive of index values in the ${ }^{*} \mathrm{CI}$ format taking into account fresh data. In the computation of ${ }^{*} \mathrm{CI}$ (VCI, IVCI, TCI) indexes, matrices of MAX, MIN extremum values are updated in every pixel throughout the period of monitoring. Such procedure is associated with the special aspects of computation of this group of indexes.

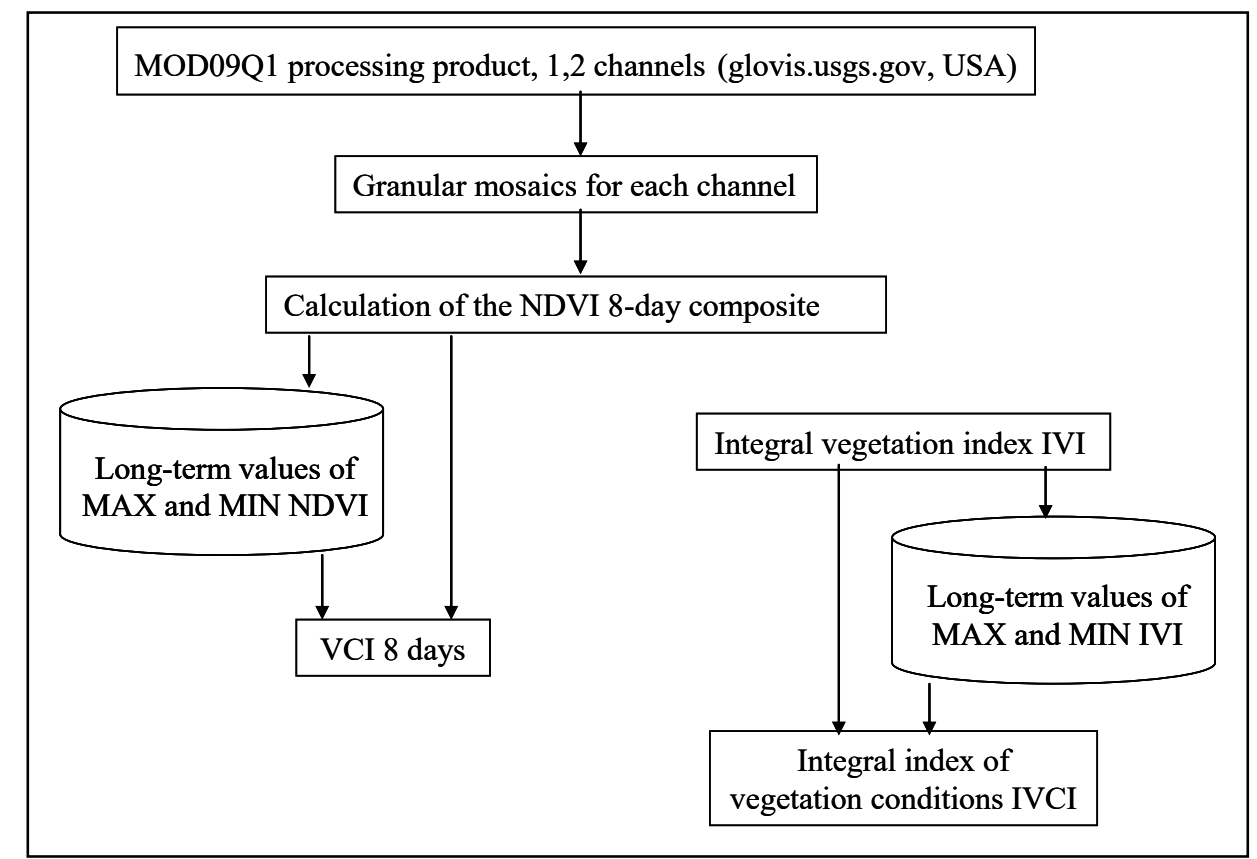

Fig.2. Computation scheme of a set of vegetation indexes based on MODIS data (8-day aggregates)

For this purpose, it is understood that if data of each new growing season is used for computation of the NDVI and IVI values, all long-term series must be recalculated for all other indexes. This is the reason of "weighing" of an index value in the long-term series of values. Notwithstanding the fact that this is an automated procedure, it requires significant computation time and a vast amount of re-computed information. For instance, the number of created files and amount of computed data during update of time series of VI data in 2020 are presented in Table 2.

Table 2. Update of Archive of Vegetation Indexes with the Use of Data for the Year of 2020 (April - October)

\begin{tabular}{|c|c|}
\hline Satellite data, vegetation indices & Number of created files \\
\hline MOD09Q1 & 162 \\
\hline NDVI & 162 \\
\hline NDVImin & 162 \\
\hline NDVImax & 162 \\
\hline VCI & 27 \\
\hline IVI & 6 \\
\hline IVImin & 6 \\
\hline IVImax & 6 \\
\hline IVCI & 6 \\
\hline
\end{tabular}

It should be pointed out that the volume of files containing digital matrices of vegetation indexes subject to the complete coverage of the territory of Kazakhstan exceeds $4 \mathrm{~Gb}$, which often results in the delayed 
computations, and on frequent occasions in infeasibility of computation of a full matrix when the medium specs computers are employed. In the furtherance of this goal, the authors of this article developed the algorithm of generation of times series of vegetation indexes.

\section{Algorithm of generation of time series of vegetation indexes}

The algorithm of generation of time series of vegetation indexes stipulates for the following steps:

- Building of mosaics of channels 1 and 2 composed of granules blanketing the entire research territory;

- Computation of matrices of NDVI (8-day) index serving as a base index in computation of other indexes;

- An NDVI matrix filtering procedure including rejection of "outlier" values (emission values noise).

The further processing of the complete matrix becomes complicated due to heavy weight of files. Consequently:

- Division of an available NDVI digital matrix into three parts with the purpose of reduction of processing time (further procedures should be implemented separately for each part);

- Computation in every pixel of $\mathrm{NDVI}_{\min }$ values over this 8-day period throughout the period of monitoring, including the new season data;

- Computation in every pixel of $\mathrm{NDVI}_{\max }$ values over this 8-day period throughout the period of monitoring, including the new season data;

- Re-computation of the 8-day VCI values for each growing season throughout the period of monitoring with consideration to updated $\mathrm{NDVI}_{\min } / \mathrm{NDVI}_{\max }$ values in every pixel for each of three parts;

- Computation of IVI matrices by summation of NDVI values in every pixel (for each of three distinguished parts),

- Computation in every pixel of IVI $_{\min }$ values throughout the period of monitoring, including the new season data,

- Computation in every pixel of $\mathrm{IVI}_{\max }$ values throughout the period of monitoring, including the new season data,

- Re-computation of IVCI values for every growing season throughout the period of monitoring with consideration to updated $\mathrm{IVI}_{\min } / \mathrm{IVI}_{\max }$ values in every pixel.

- "Stitching" (sewing together) of each VCI, IVI, IVCI digital matrix in the unified coverage for the research territory.

Division of the available NDVI digital matrix into parts and subsequent separate processing of every part are dictated by the large file size - over $4 \mathrm{~Gb}$. This approach makes good sense as it allows for the substantial reduction of the data processing time - almost twice in spite of the expanding amount of calculation.

ENVI software developed for visualization and processing of the Earth's remote sensing data was applied for image processing and computation of vegetation indexes.

\section{Conclusion}

The article focuses on the algorithm of generation of the long-term series of vegetation indexes based on the low-resolution satellite data acquired from the MODIS space vehicle. A variety of causes triggered the necessity of generation of such algorithm:

- The digital matrices of vegetation indexes provided by the known freely available services in solving of a number of tasks fail to meet certain spatial and time parameters;

- Generation of digital coverage of vegetation indexes within the limits of immense territory (an aggregate of regions, Republic) is a challenge due to the large volume of processed files and processing time.

The developed algorithm was applied across the territory of Kazakhstan. As a result, the long-term archive of vegetation indexes (2001-2020) applicable to the territory of Republic with the spatial resolution of $250 \mathrm{~m}$ and 8-day rate of frequency was created for the NDVI, VCI differential indexes. The archive provides a basis for an analysis of changes of the underlying terrain, trend determination and forecast of these changes. The range of use of the set of indexes is quite broad: changes of state of vegetation cover, 
water bodies, ecological challenges, agricultural tasks and emergencies. Proposed algorithms are simple and may be applied in any areas.

\section{Acknowledgements}

The research was supported by the Ministry of Education and Science of the Republic of Kazakhstan, Grant number AP08957145

\section{REFERENCES}

1 Atlas "Deciphering multispectral aerospace imagery: Methodology and results"- Moscow: Science - Berlin, Akademi-ferlag, 1982. - 83 p. [in Russian].

2 Lupyan E., Balashov I., Burtsev M., Efremov V., Kashnitsky A., Kobets D., Krasheninnikova Y., Mazurov A., Nazirov R., Proshin A., Sychugov I., Tolpin V., Uvarov I ., Fleetman E. Creation of technologies for building information systems for remote monitoring. Modern problems of remote sensing of the Earth from space, 2015, Vol. 12, No. 5, pp. 53-75 [in Russian].

3 Ramapriyan H. K. Development, Operation and Evolution of EOSDIS - NASA's major capability for managing Earth science data, CENDI/NFAIS Workshop on Repositories in Science \& Technology: Preserving Access to the Record of Science, 2011, November 30, $31 \mathrm{p}$.

4 Lupyan E., Savorskiy V., Shokin Yu., Aleksanin A., Nazirov R., Nedoluzhko I., Panova O. Modern approaches and technologies for organizing work with Earth remote sensing data for solving scientific problems. Modern problems of remote sensing of the Earth from space, 2012, Vol. 9, No. 5, pp. 21-44, [in Russian].

5 Official websites use.gov. Available at: https://glovis.usgs.gov/

6 GDAL/OGR user docs. Available at: http://gis-lab.info - an independent information resource dedicated to Geographic Information Systems (GIS) and Earth Remote Sensing (ERS).

7 Kogan F. World droughts from AVHRR-based vegetation health indices. EOS, Trans. American Geophys. Union, 2002, No. 83, pp. 557-564.

8 Cherepanov A.S. Vegetation indexes, Geomatics. Moscow, 2011, No. 2, pp. 98-10, [in Russian]

9 Rouse J. W., Haas R. H., Schell J. A., Deering D. W. Monitoring vegetation systems in the great plains with ERTS. Third ERTS Symposium NASA SP-351, 1973, Vol. 1, pp. 309-317.

10 Kogan F.N. Remote sensing of weather impacts on vegetation non-homogenous areas. Int. J. of Remoute Sensing, 1990, Vol.11, pp. 1405- 1419.

11 Kogan F.N. Application of vegetation index and brightness temperature for drought detection, Adv. Space Res. 1994, Vol. 15, No. 11, pp. 91-100.

12 Spivak L., Vitkovskaya I., Batyrbayeva M. Analysis of inter seasonal variations of productivity of vegetative cover of Kazakhstan using temporal remote sensing rows. News of Nat. Acad. of Sci. of Kazakhstan. Phys. Math. Ser. 2008. No. 4, pp. 29 - 32. [in Russian].

13 Belenov A.V. Standard processing levels and formats for presenting remote sensing data from space. World experience, Geomatics. Moscow, 2009, No. 4, pp. 18 - 20. [in Russian].

Article accepted for publication 23.04.2021 